Fall 1992

\title{
Why Johnny Can't Escribir: Composition and the Foreign Language Curriculum
}

\author{
George Greenia \\ College of William and Mary, gxgree@wm.edu
}

Follow this and additional works at: https://scholarworks.wm.edu/aspubs

Part of the Modern Languages Commons

\section{Recommended Citation}

Greenia, George, Why Johnny Can't Escribir: Composition and the Foreign Language Curriculum (1992). ADFL Bulletin, 24(1), 30-37.

https://scholarworks.wm.edu/aspubs/589

This Article is brought to you for free and open access by the Arts and Sciences at W\&M ScholarWorks. It has been accepted for inclusion in Arts \& Sciences Articles by an authorized administrator of W\&M ScholarWorks. For more information, please contact scholarworks@wm.edu. 


\title{
Why Johnny Can't Escribir: Composition and the Foreign Language Curriculum
}

\author{
George D. Greenia
}

ADFL Bulletin Vol. 24, No. 1 (Fall 1992), pp. 30-37

ISSN: 0148-7639

CrossRef DOI: 10.1632/adfl.24.1.30

Copyright (c) 1992 by The Association of Departments of Foreign Languages

All material published by the The Association of Departments of Foreign Languages in any medium is protected by copyright. Users may link to the ADFL Web page freely and may quote from ADFL publications as allowed by the doctrine of fair use. Written permission is required for any other reproduction of material from any ADFL publication.

Send requests for permission to reprint material to the ADFL permissions manager by mail (26 Broadway, New York, NY 10004-1789), e-mail (permissions@mla.org), or fax (646 458-0030). 


\section{Why Johnny Can't Escribir: Composition and the Foreign Language Curriculum}

\section{George D. Greenia}

THE intermediate- or advanced-level writing class for foreign language majors is one of the most durable components in the traditional curriculum. Though sometimes designated exclusively a course in foreign language composition, it is just as often packaged with advanced conversation and grammar. Frequently, however, the writing component is not taken seriously, and many teachers bundle writing practice with their other activities and give it a decidedly subordinate role. I have taught such a course for years in alternation with colleagues in my university and, like many other professionals in the field, we have concurred with some chagrin that conflated areas of concern like conversation, composition, and grammar cannot receive adequate attention in one class (Gutiérrez). The joint billing in the course catalog at least gave us the flexibility to modify content as different instructors stepped in.

"Writing" has many meanings, but, as used here, it entails learning to craft clear sentences and arguments that reveal the mind of the writer and engage the critical interest of a reader. Even offerings officially labeled courses in writing and devoted to composition alone may be listless and unfocused affairs. Whether students are promised a course completely devoted to writing or one in a combination of skills that presumably reinforce writing, their progress by the end of their college program is frequently marginal. Two traditional assumptions underlie this neglect of writing within and across the language curriculum. First, a great deal of the writing done in foreign language courses is considered an adjunct to a more "worthy" goal, mastering grammar-an objective that may be endorsed all the more keenly because the designated writing course is not uncommonly the last grammar course in the undergraduate curriculum. Second, a truly autonomous writing course might end up an odd satellite in the curriculum, marginalized by faculty members unfamiliar with its true purpose who do not see it as related in content or purpose to other advanced Spanish, French, or German courses in the major or minor. "Writing about what?" is the question that would drive any evaluation of the course by other instructors in the language concentration. And the only evidence they might seek for the writing program's success would be the grammatical quality of the papers generated in later courses in literature and civilization.

Ideas about what writing is, how it helps students learn a foreign language, and what it can ultimately be used for have all changed in recent years. For language instruction in general there has been a major shift from the teaching of langue, with its paradigm of normative input-language replication, toward the teaching of parole, with its paradigm of authentic input-language creation (Swaffar 33). In particular, we now know that learning to write well demands considerably more than mastering grammar. Research suggests that writing merely to learn grammar seems to benefit neither, whereas students unconsciously absorb considerable linguistic sophistication through extensive reading and writing within a communicative community. Most writing done in foreign language classrooms in the past consisted of transcription exercises on the phrase or sentence level, exercises that did not train students to frame extended arguments and expositions. It certainly did not require critical thinking. If students ran aground writing papers for subsequent courses in their second language, the reason may have been that practice in real writing tasks began too late and suffered from shortsighted goals. Johnny can't escribir mostly because we have not trained him to.

The energy inherent in a fresh look at writing for foreign language study will ultimately suggest class activities and assignments that are clearly emerging in English composition (Beach; Berlin; Hedge; Osterholm) but barely being explored in second-language work. The recent exceptions to our slow assimilation of this territory have generally

George D. Greenia is Associate Professor of Modern Languages and Director of the Program in Medieval and Renaissance Studies at the College of William and Mary. 
been nourished by work on English as a second language (Adelson; Bereiter and Scardamalia; Boyle and Peregoy; Connor and Kaplan; Kroll; Whalen). A few authors of second-language textbooks are now making substantive contributions to expanding our thin repertoire of opportunities for writing (Bretz, Dvorak, and Kirschner; Kulick and Toner; Valdés, Dvorak, and Hannum). My comments here are meant to provide a rationale for improved curricular design. Actual course content will vary according to the skill level, the mission of the department and institution, the interests of the instructor, and the writing needs of the students.

Rethinking the principles for using writing across the foreign language curriculum, and not just in a designated foreign language writing course, is a stimulating professional challenge. And an unexpected offshoot is a revalidation of the alliance of composition, conversation, and grammar, but with the last two now clearly at the service of the first. The following list of practical guidelines offers points of departure for making writing a central concern throughout the process of learning a new language.

1. The writing course should have its own place in the curriculum, but it should not stand alone as the sole undergraduate writing experience in the second language.

Writing practice in undergraduate foreign language programs might be graphed in two ways, representing "poor" and "good" models.
Even what I have labeled a "poor" or insufficient program of writing in an undergraduate curriculum might be somewhat optimistic for many colleges and universities. It suggests that at least during the lower-level courses preceding whatever is designated "the composition course," there will be real writing practice, as opposed to transcription or sentence-transformation exercises. This practice would include doing simple communication exercises, listing, composing social notes and invitations, leaving messages for third parties, reporting news, giving advice, and so on (see Larson and Jones; Gaudiani). Ideally, there will be a progression toward higher registers of free written discourse, although in many programs the lower registers are rarely practiced again after initial exposure to them. They never become reliable writers' tools by themselves or serve as building blocks for higher-order skills. Then during the writing course some unspecified process is supposed to take place that will enable students who do advance to upper-level courses to absorb the erudition pumped out at them and, at the end of the term, to produce massive chunks of polished formal-register writing (with good vocabulary and grammar, of course). It is not an unlikely scenario: many upper-level courses conclude with a single major essay assignment, ten pages on Don Quijote or Baudelaire or Faust.

A better model would embrace considerably more writing practice of all sorts throughout elementary and intermediate courses. The writing course, however it is sequenced in the curriculum, is a watershed experience,

\section{Writing in Undergraduate Programs}

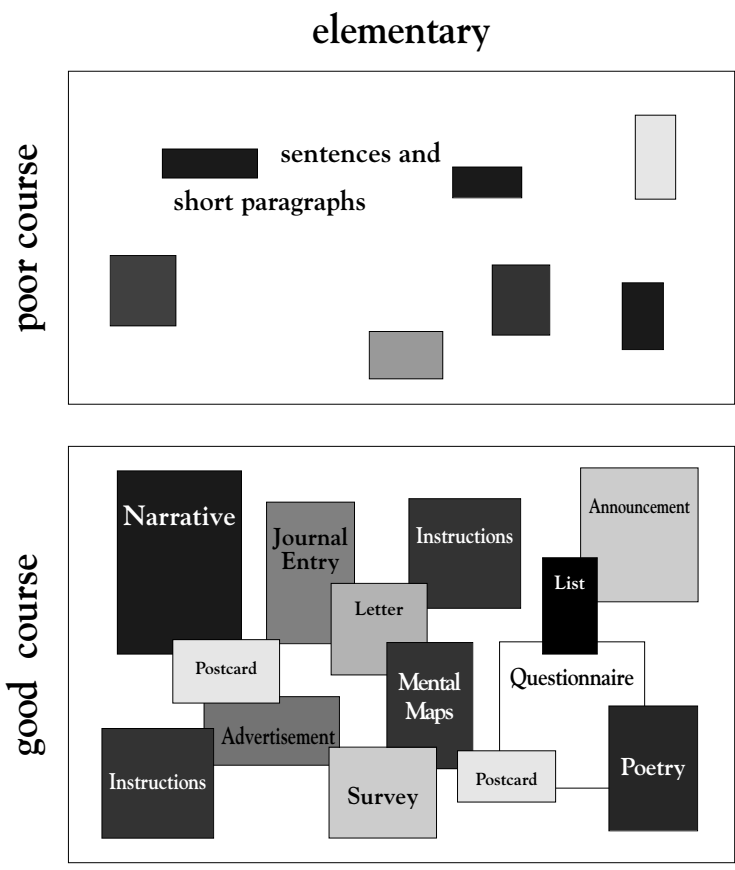

advanced
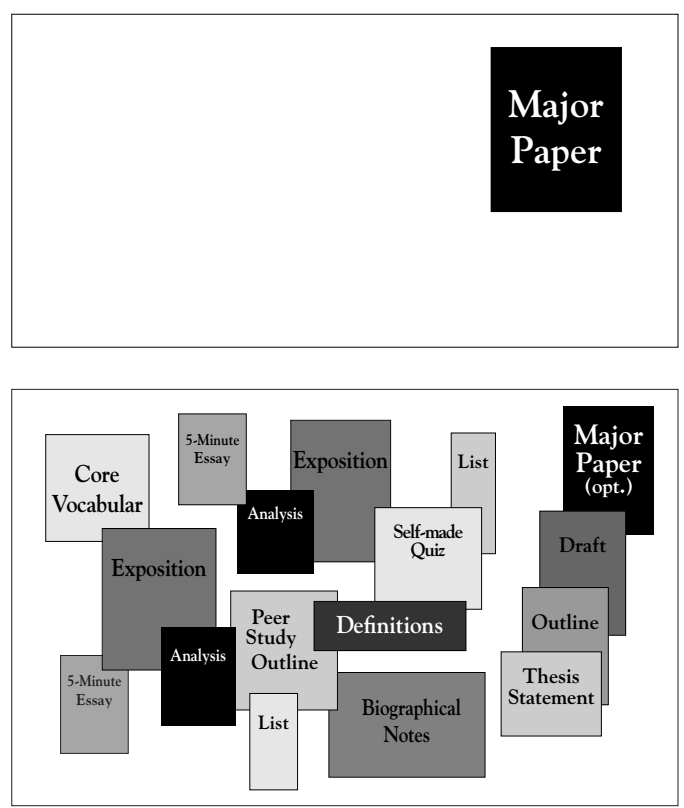
but professors teaching other language classes should not expect students to emerge from it able to write consistently at an advanced level. Our upper-level literature and culture courses should include many forms of writing practice, a good deal of it "guided" writing in some form. The writing and prewriting experiences should be interrelated and tied to the content of the course. Only a few writing tasks should require formal discourse, and assigning a small project in this register as a capstone exercise should be an option, not a necessity. While this model involves a lot more work in course and curriculum management for the teacher, it will pay off in the superior writing and language skills the students acquire and in the amount of content they absorb. Not all the exercises have to be graded by any means, but all should be read for content and responded to. ${ }^{1}$

Although this configuration of expectations differs from the traditional one, it may be more realistic about student ability. The ACTFL guidelines for proficiency in writing provide a logical and fully articulated statement of expectations for written performance from NoviceLow to Superior levels, nine divisions in all (Magnan; Omaggio). It is no small advantage to a teacher to know which language functions are mastered in each proficiency tier and to understand that consistently satisfactory performance in one level implies competence in each lower level as well. For instance, learners who can perform Intermediate-High tasks ("write simple letters, brief synopses and paraphrases, summaries of biographical data and work experience, and short compositions on familiar topics," etc.) will have control of lower-level functions such as listing, reproducing memorized material, filling out simple forms, and describing daily routines. (Terry describes both creative tactics for devising writing assignments and astute models for holistic grading.)

The ACTFL guidelines also caution us about what sorts of foreign language writing assignments we give. The normal level in first- and second-year high school and firstyear college programs is Novice. Four years of high school work, or four semesters in college, will probably only yield students working in the Intermediate range (LiskinGasparro). Omaggio suggests that "students who major in language in college might be expected to write rather consistently on the Advanced Level, whereas the Superior Level is rarely attained before the graduate level of study in a foreign language" (233).

Since most of our college language majors never achieve the Superior levels-at least not in oral proficiency, the only skill thoroughly tested to date-teachers who become frustrated with student performance may simply be assigning tasks beyond the learners' ability. A standard literary or culture writing assignment, like "Describe Sancho Panza's motivations in deceiving Don Quijote" or "Comment on facets of the unbalanced personality of Pascual Duarte," inasmuch as it involves argumentation and analysis, is decidedly an Advanced- if not a Superior-level enterprise.
Merely because students can handle similar exercises in their English classes, we cannot automatically assume that they have the lexical or syntactic muscle to do comparable work in a foreign tongue. ${ }^{2}$

Inadequacies in this area could understandably cause a loss of face for us as instructors and frustration for the undeniably bright college students enrolled in our advanced courses. We know that the same young adults are more than competent to do literary or cultural analysis in their native tongue, and we (and they) feel stymied when their language skills break down as they try to do similar work in their second language. Our discouragement could even lead us to unfounded suspicions that language majors are just not as smart as their peers in physics or psychology or that the language barriers confronting class lectures and discussions and student writings will condemn both teachers and students always to work on a relatively inferior intellectual level. We should remember that, while our students may not be able spontaneously to "use written language effectively for formal and informal exchanges; hypothesize and conjecture; write all types of correspondence and short research papers; support points of view, defend hypotheses" (Superior-level functions [Omaggio 237]), they can perform other partially guided or structured writing tasks that display deep critical thinking and advance their language skills.

2. Writing in the foreign language in itself has not proved an effective vehicle for learning grammar. Improving grammatical accuracy and usage should not be a goal that controls the design of the course, although it will probably be a strong by-product. When students learn how to check their own grammar during the editing process (reuriting, proofing), their long-term retention tends to be significantly better.

Current research suggests that teacher-learner grammars-as distinct from native speaker (internal) grammar or descriptive (linguists') grammars-are not ultimate goals but mere aids to language use. The grammatical control we hope our students will acquire is best absorbed when writing is foregrounded as a communicative skill. In fact, research on second-language writing has come to two conclusions: "(1) writing improvements are unrelated to grammar study, whether of traditional or transformational variety, and (2) intensive correction of student writing, which has a negative effect in terms of student attitudes and motivation, has little positive effect at all" (Dvorak 151-52).

Having a personal investment in the content of a text, even a formal text, lends an urgency to composition, obligating the writer to communicate clearly. Under those circumstances, the writer willingly consults a reference grammar when it can best serve this purpose, principally during the final revision and editing (Lalande). Incorporating grammar manuals as reference tools rather than as primary texts actually enhances retention of the grammar that language learners look up for themselves. Mistakes 
that are challenged by a sympathetic reader because the desired message is coming across muddled are mistakes that trigger real learning when the text can be modified or revised grammatically (Dvorak).

According to Ballman, the syntactic complexity and accuracy of students' writing do not benefit from grammar study either. She also suggests that a single term of study may not be enough to effect a measurable change in writing quality; an extended program of conscientiously diversified writing assignments over several semesters is probably necessary to produce substantive improvement. Faculty members would have to cooperate closely to reinforce writing skills in different contexts and beyond the designated "writing course."

Grammar, of course, still has a place in the curriculum at the intermediate and advanced levels, and specifically in the designated writing course. Research merely suggests that grammar study does not improve the clarity or craftsmanship of student writing, nor does focusing on grammar correction in writing samples. Whether the instructor supplies the corrections or inserts coded clues and demands recopying, students show no improvement in formal accuracy in subsequent assignments. Lalande found, however, that his student subjects did improve significantly in grammar and orthography by having error-correction codes inserted into their compositions if they kept track of their own recurring mistakes. He favors the correction of all surface errors, but his study does not try to assess the quality of the communication, argument, or structuring of the writing assignments. In contrast, Semke concurs with Dvorak that "corrections do not increase writing accuracy, writing fluency, or general language proficiency, and they may have a negative effect on student attitudes, especially when students must make corrections by themselves" (195). The students in Semke's experiment who received only responsive comments on their work and whose grammar was not corrected at all actually spent the most time on their assignments and were the most motivated to seek advice on correcting the mechanics of their writing.

By coaching learners on key elements of good style and on conventions of diction and format for the genres practiced and by monitoring their steps in the writing process, the composition instructor can accelerate the process of their gaining a simple performance mastery of written communication. This type of coaching is not the whole answer, of course, because writing courses alone cannot transform a student into a truly proficient writer. Skill in creating written discourse is too complicated ever to be transmitted (i.e., systematically learned) through a formal course. Krashen and other authors cited by him (especially Smith) have shown that real competence in writing must stem at least in part from the learners' reading a large volume of texts that model the types of prose they will eventually create. Reading allows an individual to acquire a sure sense of how a given sort of text is forged and presented to a reader. But there are needs besides voluminous reading. Smith points out that even good readers are not transformed into good writers unless they perceive that their efforts will be successful (i.e., that the process will not be too difficult or onerous) and that they are already members of the implicit discursive "club," the community that produces and consumes the forms of written discourse in question (Krashen 25-26).

The consequences for the foreign language curriculum of this natural sequence of extensive reading and then writing are not entirely clear. Should students take a comprehensive writing course in English before undertaking any of the required courses for the foreign language concentration, on the presupposition that a knowledge of generic writing styles will readily transfer from one language to another? Or would a foreign language composition course covering widely diverse types of writing and taken early in the major or minor better serve students' personal long-range language goals and provide stronger carry-over skills for later courses? Are German and English personal letters or interpretative essays, for instance, so different from each other that examples in the target language have to be explicitly rehearsed? ${ }^{3}$ Is the recursive link between reading and writing more a matter of exposing students to an ample variety of syntactic structures and functional constructions, so that they will absorb enough language to build their own second-language voice (Cummins, cited by Krashen)? Does a writing course make any sense if students have not read enough second-language material in previous courses? This last consideration can be a major stumbling block, since many programs favoring traditional grammar instruction shortchange reading, making almost no attempt to foster reading for pleasure in the foreign language or, in the now classic phrase, to "get kids hooked on books." This essay offers provisional answers to some of these questions, but firm empirical results await further research.

Finally, is the ability to produce serious writing (academic or otherwise) really a skill that can only be expected of advanced, perhaps graduate-level students? Clearly the answer is no. Writing is a complex craft, but it has its lower registers; and while the volume of language produced is low compared with that involved in speaking, listening, and reading, the payoff in enhanced language competence (including grammatical competence) is inversely high. Reserving composition instruction for upper-level courses presents a real danger: if students must wait to practice writing until near the end of a traditional language program, when they are exposed almost exclusively to literary texts, they may be equipped to write only about literature.

3. A foreign language writing course is a valuable language course in and of itself; it is not a service course to prepare students for something else.

We often hear colleagues claim that students who have completed the writing course still have problems with grammar or that if we are not preparing them to write 
good papers for the advanced courses we are not helping them face their future. First, I hope their future as writers is a little brighter and more varied than what that comment implies. Rehearsing some of the simpler registers of self-expression in a language is a profitable learning strategy in itself (Magnan). Besides, students may need or prefer to express themselves in writing in ways we cannot predict. Practicing many levels and forms of written discourse gives them the greatest flexibility. And, as Horning has shown, mastering academic discourse even in one's native language is like learning a second language. Such writing has its own unique rules and conventions, and its own psycholinguistic features differ from those of oral language. If training in academic prose is chosen as an explicit goal of a foreign language curriculum, it will demand that teachers commit themselves to a special methodology and provide students with extensive practice.

Second, we can change the nature of our students' future as members of a community in dialogue by assigning different writing tasks. Academic discourse also has its own building blocks. Exercises in isolating elements of a literary author's style-techniques of sequencing paragraphs, metrical diversity, lexical patterning, and so oncan be transformed into short prose expositions that can be springboards to higher-level free-writing analytical assignments. But we should share such strategies with our colleagues; there is no way to refute a charge like "Your writing students did not come into my course adequately prepared." "Prepared for what?" is the question. Actually, we all have rather different hopes for our students' writing, and we should each accept responsibility for preparing students to learn modes of formal analysis course by course. Step 1 is to liberate the writing course from misplaced expectations.

4. Second-language writing should not be conceived of as primarily a literature course in another form. Neither is it meant to convey a certain corpus of cultural information, although a rich cultural component makes good use of our knowledge and experience as a writing community, helps keep interest high, and allows the vocabulary of the target language its logical semantic field of collateral relations. Writing in the foreign language should aim at an increasingly subtle control of authorial voice, social register, and reader appeal.

The grammar-composition course is one of the most stubbornly traditional offerings in foreign language curricula, and with the recent theoretical investments in (and pedagogical celebration of) oral-aural language skills, competence in writing has not had as much attention from the best minds in our field as have these more interactive proficiencies. Usually positioned at the intermediate or advanced level, the grammar-composition course, as I have noted, often serves as the capstone to students' formal language training, after which they "graduate" to their "real goal" of literary study.

But we need to remember that grammatical exactitude and literary finesse- the goals closest to our hearts as lan- guage teachers, trained linguists, and literary critics-may not be the personal goals of our students. Many students have fallen in love with Hispanic or francophone or German culture and want to gain depth in it without necessarily duplicating our careers. We should bear in mind that the educational and social purposes of written communication go far beyond the study of literature, or else we may find that we are really using a foreign language to teach a creative writing course as well as a grammar course, and students may feel that they cannot live up to the expectations of either.

Well-written pieces in any language register (informal to very formal), including literary (very formal) registers, can serve as effective models if they can help students derive patterns for their own writing. Composition courses should include forms distant from academic writing and apart from the disciplines others associate with our professional publications. Topics covered can form a logical series over the term ("The Individual and Society between Cultures"), or they can be organized into self-contained subdivisions ("Relations between the Sexes," "Alcohol Here and Abroad," "How Spaniards Handle Personal Stress"). Writing for content-communicating ideas and problems that matter to writers and their reading community-is the best way to keep writing from devolving into grammar practice and to help it be a critical intellectual exercise for all concerned.

Language registers are not the same as genres, although expanding the repertoire of functions of writing to include such tasks as producing short notes and messages, filling out forms, and taking lecture notes will effectively cover all the natural registers of written language use. It is crucial to strive to integrate all levels of writing, since it is impossible to tell what sorts of writing students will have to produce in the future. This breadth of exposure should also encourage them to use their second language in a wider variety of contexts when opportunities appear.

In my own classes, students are required to make weekly contributions to a public bulletin board: to recommend movies, review recent rock concerts, look for study partners in chemistry, or advise fellow students, during preregistration for the coming term, about which professors to sign up for and which to avoid. The medium allows total freedom of content but mandates that the message be brief, low-register, and direct. My students and I also exchange dialogue journals that probe serious topics such as date rape on campus, AIDS, the qualities of a new college president, and the merits of a sorority system that enforces superficial conformity and superficial friendships. Here the register is higher and more deliberative, the voice more intimate although still public, since the most incisive reflections will be circulated electronically within the class (Greenia). Students in my literature classes are required to contribute a certain number of exam questions, which they sign and post for everyone. This task is a writing exercise in itself, and any student 
who runs aground on one of these questions is free to call the author to discuss the answer in the target language, a conversation that serves both students as a prewriting exercise before the exam.

5. A focus on writing for exchanging and engaging ideas puts students with varying language strengths on a more nearly equal footing, since it is their ideas that count most here, not the quality of their grammar. Mechanisms for peer review and coediting can put some students' strength in grammar at the service of their classmates.

The composition class is often the course where undergraduate language majors and minors coming up through the ranks meet the students coming in from outside. If a foreign language department's multiple-skills "writing" course is really a conversation class, where fluency and vocabulary are prized, or a grammar review class, where morphological control and syntactic intuition get academic reward, then instructors are going to end up with a desperately mixed group. This is a persistent (and understandable) complaint of teachers who handle this course: students range so widely in ability that some are lost, others are bored, and all are frustrated, intimidated, or defensively smug for their own reasons.

But once teachers move the enterprise from a realm based on mechanical production to one based on content and ideas, the group tends to level out and collaborate on the basis of its members' individual gifts. Male and female students clarify their personal positions on date rape as they design campus brochures in the target language to alert incoming foreign students about how Americans understand their own dating scene. Students with clear notions about how to make the college or university more environmentally responsible can collaboratively design second-language fliers and action checklists for other readers of that tongue, with some students contributing more by providing ideas and others by editing and correcting grammar. The emphasis should be on peer-managed writing projects that have specific communicative goals.

The acquisition of a full range of writing skills, however, often has only an uncertain relation to the learning tasks we assign. Researchers are still a long way from identifying a firm sequence of writing types as they are absorbed by second-language learners. Progress in language skills is rarely orderly or clean, and students' intimacy with a given subject or their unique cognitive habits (a taste for allegory, a vivid sense of color or sound, a combative spirit) may affect a particular assignment, resulting in an unexpectedly high level of writing. Students should choose what they want to say and a personally effective style; we facilitate the recursive processes and show students how to apply metaskills (self-correction, peer-review strategies, adjustment for audience). As teachers, we must encourage students to try their hand at a wide variety of writing styles and to capitalize on the strengths that emerge, so that they will continue to grow as writers after they have passed through our courses.
Such collaboration is somewhat counterintuitive within our profession. We almost always compose in solitude; ego investment and personal identification with what we write are high-logically enough, since academics get themselves jobs, promotions, and raises with what they write. But most of the writing our students will be doing in class and in the future aims at refining and sharing what they know. (That is our general goal too; it just gets overshadowed by our apprehensions about professional survival.) In contrast to the kind of writing we are used to, collaborative writing that receives large amounts of friendly advice and peer editing is the norm for nonacademic research, journalism, advertising, and even office memos. The writing habits of those in educational institutions happen to be somewhat at odds with those common in nonacademic settings, and we need the flexibility and objectivity to validate heterogeneous forms of discourse.

6. All discourse generated in a writing class should be public rather than private.

An insistence on public discourse may also run counter to common practice in some foreign language teaching. We tend to give writing assignments that invite personalization and self-disclosure so that students will heighten their ego investment in their tasks. A healthy segment of our generation of academics, however, consists of the sensitized survivors of the sixties, seventies, and eighties, and the last thing we want to do is embarrass our students in public (even if we sometimes joke in private that certain intractable students almost deserve it). For these reasons we shield our students from having their writing exposed to the public forum. A few professors have told me that they feel strongly about the privacy of the dialogue they have with their students and would never let anyone else read their students' papers.

The trouble with our hypersensitivity about privacy is that students are being asked to write for a single reader. This familiarity understandably leads to a great deal of elision in students' prose as they trim away premises and information that they presume can be taken for granted because it has already been discussed in class or in the hall. Sometimes a student is surprised and disgruntled when the teacher returns a paper with the comment that "the tone is too personal or informal" or that "too much is left unstated." What may have happened here is that the writer and the reader had different implicit audiences in mind.

Some teachers encourage individual involvement in student writing and systematically reward disclosure and personal investment. Now we are talking not about professional discourse but about confessional texts posing as informational pieces or literary analysis. Students who are shy or naturally circumspect or just private people are disadvantaged, and those who can feign intimacy on demand are probably not developing a skill that has much of a future. When professors ask for students' innermost reflections, the request at best is intrusive and at worst voyeuristic. If 
a text cannot be read in a public forum, it probably should not be required from members of a public forum.

\section{A well-developed oral component can enliven the initial} exchange of ideas, help define topics, suggest ways of structuring written presentations, concretize second-language lexical resources, and generally serve as the platform for prewriting activities.

The oral component I advocate for the writing course is, gratifyingly, conversation with a purpose. Many "class discussions" are just idle speculation—or hot air-that students rightfully suspect is subversively meant to get them to use the subjunctive: "What do you think college will be like in the year 2050? Start your sentences with Es posible que...." Exploratory talks that are honestly targeted at a practical end, like an eventual written statement of a controversial position, should make for more attentive discussion, for brainstorming, for allowing hierarchies of theme to emerge, and for the absorption of key lexical terms before students undertake the first drafts of an assignment. Informal oral exploration of a topic is undoubtedly the best starting point for the creation of a written dialogue (Houpt). Most current composition textbooks, like most foreign language texts on the market, are structured according to grammatical categories or traditional genres of written communication, with no consideration given to what students themselves might want to write or to the different registers they need to practice and will need in the future.

The change from privileging academic writing as a product to be scrutinized to investing in writing as a process that strengthens many aspects of language learning has made "writing across the curriculum" one of the themes of the eighties and nineties. The merger of secondlanguage practice in a variety of genres with the higherorder writing skills appropriate for advanced courses will supply the tools necessary for the critical thinking and expression that we strive to develop in our majors and minors. Many recognized writing specialists who were originally trained to teach literature find that focusing on writing enhances their overall success as teachers of language and literature (Chapman). We all just need a certain detachment from our background in grammar and literature to guide our students better toward fully creative learning through writing. ${ }^{4}$

\section{Notes}

${ }^{1}$ The problems of handling a large volume of student work can be lessened considerably by the use of text-editing programs on personal computers. Elsewhere I describe a model for organizing a writing-intensive foreign language class (either composition or literature) entirely on computer diskettes (Greenia).

${ }^{2}$ Reliance on the Advanced Placement Examination guidelines for holistic evaluations of a text has been suggested, at least for grading purposes (Magnan; Terry), but these are global performance evaluators, briefly stated on purpose for the benefit of diverse graders facing masses of papers from students all of the same age and scholastic level. These guidelines were never meant to serve as a fine-tuned diagnostic tool to provide feedback for students or teachers, and in any case the AP Exam protocols would barely measure the progress made from semester to semester, let alone from assignment to assignment.

${ }^{3}$ Examples in the target language may well be required; native speakers and writers of French and Spanish and German do seem to reveal language-specific, or at least national, idiosyncrasies in framing their arguments. "Passing for native," however, is a crucial goal only if you are a spy. Students will inevitably express themselves in their native psychological idiom no matter what the language; an intuitive feel for the rhetorical logic of another culture and language, if it is ever acquired, will be gained late in language contact, by prolonged exposure rather than by formal instruction. That fact, however, certainly does not diminish what students can accomplish in cultured written discourse on their own terms. On writing styles across cultures, see Krashen 38 and Kaplan. In any case, Krashen reports a marked correlation between strong first-language readers and strong second-language writers.

${ }^{4}$ I would like to express my thanks to Colleen Kennedy, Katherine Kulick, and Teresa Longo (William and Mary) and to David Paulson (Univ. of Illinois) for their thoughtful comments on earlier drafts of this paper. Responsibility for the opinions expressed remains, of course, entirely my own.

\section{Works Cited}

Adelson, Leslie A. "History, Literature, and the Composition and Conversation Class." Modern Language Journal 72 (1988): 13-20.

Ballman, Terry Lynn. "Syntactic Complexity and Accuracy in L2 Writing: Improvement in One Semester?" Language and Language Use: Studies in Spanish. Ed. Terrell A. Morgan, James F. Lee, and Bill VanPatten. Lanham: UP of America, 1987. 233-40.

Beach, Richard. "The Effects of Between-Draft Teacher Evaluation versus Student Self-Evaluation on High School Students' Revising of Rough Drafts." Research in the Teaching of English 13.2 (1979): 111-19.

Bereiter, Carl, and Marlene Scardamalia. "Does Learning to Write Have to Be So Difficult?" Learning to Write: First Language/Second Language. Ed. Aviva Freedman, Ian Pringle, and Janice Yalden. New York: Longman, 1983. 20-33.

Berlin, James A. "Contemporary Composition: The Major Pedagogical Theories." College English 44 (1982): 765-77.

Boyle, Owen F., and Suzanne F. Peregoy. "Literacy Scaffolds: Strategies for First- and Second-Language Readers and Writers." Reading Teacher 44 (1990): 194-200.

Bretz, Mary Lee, Trisha Dvorak, and Carl Kirschner. Pasajes. New York: McGraw, 1987.

Chapman, David W. "Conflict and Consensus: How Composition Scholars View Their Discipline.” Profession 87. New York: MLA, 1987. 43-45.

Connor, Ulla, and Robert B. Kaplan. Writing across Languages: Analysis of L2 Written Text. Reading: Addison, 1987.

Cummins, J. "The Role of Primary Language Development in Promoting Educational Success for Language Minority Students." Schooling and Language Minority Students: A Theoretical Framework. Los Angeles: Evaluation, Dissemination and Assessment Center, California State U, 1981. 3-49. 
Dvorak, Trisha R. "Writing in the Foreign Language." Listening, Reading, and Writing: Analysis and Application. Ed. Barbara H. Wing. Middlebury: NEC, 1986. 145-67.

Gaudiani, Clair. Teaching Writing in the FL Curriculum. Washington: CAL, 1981.

Greenia, George D. "Computers and Teaching Composition in a Foreign Language.” Foreign Language Annals 25 (1992): 33-46.

Gutiérrez, John R. "Overcoming Anarchy in the Advanced Language Class.” ADFL Bulletin 21.2 (1990): 41-45.

Hedge, Tricia. Writing. Oxford: Oxford UP, 1988.

Horning, Alice S. Teaching Writing as a Second Language. Carbondale: Southern Illinois UP, 1987.

Houpt, Sheri. "Inspiring Creative Writing through Conversation." Foreign Language Annals 17 (1984): 185-89.

Kaplan, Robert B. "Contrastive Rhetorics: Some Implications for the Writing Process." Learning to Write: First Language/Second Language. Ed. Aviva Freedman, Ian Pringle, and Janice Yalden. New York: Longman, 1983. 139-61.

Krashen, Stephen. Writing: Research, Theory, and Applications. New York: Pergamon, 1984.

Kroll, Barbara, ed. Second Language Writing: Research Insights for the Classroom. Cambridge: Cambridge UP, 1990.

Kulick, Katherine M., and Frederick L. Toner. Notez bien! Les contextes de l'écriture. Boston: Heinle, 1992.

Lalande, John F., II. "Reducing Composition Errors: An Experiment." Modern Language Journal 66 (1982): 140-49. Rpt. in Foreign Language Annals 17 (1984): 109-17.
Larson, Jerry W., and Randall L. Jones. "Proficiency Testing for the Other Language Modalities." Teaching for Proficiency: The Organizing Principle. Ed. Theodore V. Higgs. Lincolnwood: Natl. Textbook, 1984. 113-38.

Liskin-Gasparro, Judith. "The ACTFL Proficiency Guidelines: A Gateway to Testing and Curriculum." Foreign Language Annals 17 (1984): 475-89.

Magnan, Sally Sieloff. "Teaching and Testing Proficiency in Writing: Skills to Transcend the Second-Language Classroom." Proficiency, Curriculum, Articulation: The Ties That Bind. Ed. Alice C. Omaggio. Middlebury: NEC, 1985. 109-36.

Omaggio, Alice C. Teaching Language in Context: Proficiency-Oriented Instruction. Boston: Heinle, 1986.

Osterholm, Kathryn K. "Writing in the Native Language." Northeast Conference on the Teaching of Foreign Languages. Ed. Barbara H. Wing. Middlebury: NEC, 1986. 117-43.

Semke, Harriet D. "Effects of the Red Pen." Foreign Language Annals 17 (1984): 195-202.

Smith, F. "Reading like a Writer." Language Arts 60 (1983): 558-67.

Swaffar, Janet K. "Curricular Issues and Language Research: The Shifting Interaction.” Profession 89. New York: MLA, 1989. 32-38.

Terry, Robert M. "Teaching and Evaluating Writing as a Communicative Skill.” Foreign Language Annals 22 (1989): 43-54.

Valdés, Guadalupe, Trisha Dvorak, and Thomasina Hannum. Composición: Proceso y síntesis. New York: McGraw, 1989.

Whalen, Karen. "Pilot Study on the Nature of Difficulties in Written Expression in a Second Language: Process or Product?" Bulletin de l'ACLA/Bulletin of the CAAL 10.1 (1988): 51-57. 